\title{
Effects of fish oil on cell proliferation and liver injury in an experimental model of acute hepatic injury induced by carbon tetrachloride
}

\author{
Korkmaz $\mathrm{H}^{1}$, Temel $\mathrm{T}^{2}$, Bugdaci $\mathrm{MS}^{3}$, Tekelioglu $\mathrm{Y}^{4}$, Ozoran $\mathrm{Y}^{5}$, Kapicioglu $\mathrm{S}^{6}$ \\ Selcuk University, Faculty of Medicine, Department of Internal Medicine Division of Gastroenterohepatology, \\ Selcuklu, Konya,Turkey. husein68@hotmail.com
}

\begin{abstract}
Objective: We aimed to investigate the effect of fish oil on the hepatic injury and cell cycle phases as well as cellular proliferation- regeneration in a rat model of acute hepatic injury induced by carbon tetrachloride. Background: Compensatory cell proliferation and tissue regeneration occurs as an endogenous response following chemical damage to the liver and enable animals to over come the injury. Data related to effect of fish oil on liver injury induced by chemical hepatotoxicants are controversial.

Method: 60 male Wistar-albino rats were fed either with a diet supplemented with $20 \%$ fish oil or standard rat feed for 2 weeks. After an overnight fast, rats in each group were administered either $1 \mathrm{ml} / \mathrm{kg}$ carbon tetrachloride or saline intraperitoneally.

Results: Fish oil enriched diet significantly enhanced the carbon tetrachloride - associated necroinflammatory damage, ballooning degeneration and the elevation of serum transaminases induced by carbon tetrachloride. Furthermore fish oil diet prevented cell proliferation, increased the proportion of cells in the G0/G1phase concomitant with a decrease in the proportion of cells in the $S$ phase cells.

Conclusion: Fish oil diet exacerbates the hepatic injury and prevents cell proliferation-regeneration in normal and injured liver cells. Suppression of tissue regeneration by fish oil may lead to progression of the hepatic injury (Tab. 3, Fig. 4, Ref. 31). Text in PDF www.elis.sk.

Key words: hepatic injury, fish oil, n-3 PUFAs, cell-cycle, carbon tetrachloride.
\end{abstract}

Carbon tetrachloride $\left(\mathrm{CCl}_{4}\right)$ is a classic hepatotoxicant, which causes acute and reversible liver injury characterized by centrilobular necrosis followed by hepatic regeneration and tissue repair (1).

$\mathrm{CCl}_{4}$ induced hepatotoxicity involves two phases. The first phase is cytochrome P-450 (Cyt P-450) mediated metabolism of toxic trichloromethyl free radicals (e.g. $\mathrm{CCl}_{3}, \mathrm{CCl}_{3} \mathrm{O}_{2}$ ) which initiates lipid peroxidation and leads to peroxidative degradation of cellular membranes leading to the necrosis of hepatocytes (1, 2 ). The second phase is the activation of Kuppfer and sinusoidal endothelial cells probably by free radicals and release of proinflamatory and cytotoxic mediators like tumour necrosis factor $\alpha$ (TNF- $\alpha$ ), interleukin 1 (IL-1) and eicosonoids (2-4). Those inflam-

${ }^{1}$ Selcuk University, Faculty of Medicine, Department of Internal Medicine Division of Gastroenterohepatology, Selcuklu, Konya/Turkey, ${ }^{2}$ Osmangazi University, Faculty of Medicine, Department of Internal Medicine, Division of Gastroenterology, Eskişehir/Turkey, ${ }^{3}$ Konya Education and Research Hospital, Gastroenterohepatology Clinic, Meram/ Konya/Turkey, ${ }^{4}$ Karadeniz Technical University, Faculty of Medicine, Ddepartment of Histology and Embryology, Trabzon/Turkey, ${ }^{5}$ Karadeniz Technical University, Faculty of Medicine, Department of Pathology, Trabzon/Turkey, and ${ }^{6}$ Maltepe Medical Center, Department of Gastroenterohepatology, Maltepe, Istanbul/Turkey

Address for correspondence: H. Korkmaz, Alaaddin Keykubat Champus, Selcuk University, Selcuklu Medical Faculty, Department of Internal Medicine, Division of Gastroenterohepatology, Selcuklu, Konya, Turkey. Phone: +3322415000.44645 , Fax: +3322416065 matory mediators from activated hepatic macrophages are thought to potentiate $\mathrm{CCl}_{4}$ - induced hepatic damage $(3,4)$.

Fish oil contains high amounts of omega- 3 polyunsaturated fatty acids (n-3 PUFA) including eicosapentaenoic (EPA) and docosahexaenoic acid (DHA), which are essential fatty acids. Dietary n-3 PUFAs may decrease concentration of n-6 PUFAs including arachidonic acid (ARA) in the membranes of all cell types particularly platelets, monocytes and liver cells. ARA products are proinflammatory mediators (2-series eicosanoids) whereas EPA products (3-series eicosanoids) have antiinflammatory effects. The competitive inhibitory effects of ARA and EPA on cyclooxygenase and lipoxygenase enzymes may explain this opposite inflammatory effects $(5,6)$. In addition, n-3 PUFAs also decrease TNF- $\alpha$ and IL-1 production from Kupffer cells and macrophages $(7,8)$.

Dietary interventions rich in EPA and/or DHA have been shown to keep inflammation under control and therefore are used as preventive measures against a number of illnesses such as rheumatoid arthritis, ulcerative colitis, asthma and cardiovascular diseases (9), Whereas some papers describe undesirable effects of n-3 PUFAs $(10,11)$. Supplementing the diet with n-3 PUFAs resulted in an increased lipid peroxidation (12). Dietary n-3 PUFAs have been shown to have a detrimental effect on wound healing (10). It has been also reported that fish oil rich in the PUFAs accelerate lipid peroxidation induced by $\mathrm{CC}_{4}$ but do not enhance $\mathrm{CC}_{4}$ induced liver injury (13). In contrast, Polavarapu et al (14) showed 
that fish oil caused severe liver damage in alcohol-intoxicated rats. Therefore, the effect of fish oil on liver injury induced by chemical hepatotoxicants is controversial.

Generally, n-3 PUFAs such as EPA and DHA inhibits cell proliferation in comparison to saturated fatty acid. However, some studies have shown either no impact or a positive effect of PUFAs on cell proliferation $(15,16)$. Based on these studies, higher concentrations of dietary PUFAs may inhibit cell proliferation in both rat and human population $(17,18)$. However, no information about the effect of n-3 PUFAs on cell proliferation in chemical induced hepatotoxicty is available.

The aim of this study was to evaluate the effects of dietary supplements enriched with n-3 PUFA in the form of fish oil on hepatoprotective actions in an experimental model of CC14 induced liver injury and we aimed to determine the effect of fish oil on cell cycle phases as well as cellular proliferation- regeneration in this experimental study.

\section{Materials and methods}

\section{Animals and Diets}

Male Wistar-albino rats (from Animal Research Laboratory of Uludag University Faculty of Medicine Bursa/Turkey) weighing 125-175 gr underwent experiments performed in accordance with the guidelines for animal research of the National Institute of Health and approved by our ethic committee on Animal Research. The animals were housed individually in air conditioned rooms $\left(21 \pm 1{ }^{\circ} \mathrm{C}\right)$ with controlled humidity $(50 \pm 10 \%)$ and a 12 hours (h) light/dark cycle, and were fed experimental diets for a 2 -wk period. Sixty rats were divided randomly into the groups and fed either (1) a diet supplemented by $20 \%$ (w/w) Menhaden fish oil FO (Menhaden FO - Sigma-Aldrich Chemie Gmbh, Munich,Germany) or (2) standard rat feed (SRF; Taris Chow Co., Izmir Turkey). Vitamin $\mathrm{E}$ or other antioxidants were not given to the groups supplemented with fish oil. The diets were stored at -20 ${ }^{\circ} \mathrm{C}$ and provided fresh daily. The major fatty acid composition of Menhaden FO and SRF diet was analyzed by gas chromatography (Tab.1). On the 16 th day, both groups (FO or control) were subdivided into the two subgroups and after a $16 \mathrm{~h}$ fast, either $1 \mathrm{ml} / \mathrm{kg}$ $\mathrm{CC1}_{4}$ dissolved in corn oil 1:1 (from Merck KgaA, 64271 Darmstadt, Germany) or saline injected intraperitoneally (ip) injected. Four experimental groups were labelled as follows; (1) Control (SRF-saline), (2) $\mathrm{CC1}_{4}$ (SRF- $\mathrm{CC1}_{4}$, (3) Fish oil (FO-saline), (4) FO- $\mathrm{CCl}_{4}$. Each group consisted of fifteen animals. $24 \mathrm{~h}$ after the administration of $\mathrm{CCl}_{4}$, tail venous blood was taken for serum

Tab. 1. Fatty acid continent of menhaden fish oil and standard rat feed.

\begin{tabular}{lcc}
\hline Fat composition (\%) & Menhaden fish oil & Standard rat feed \\
\hline Linoleic (C 18:2 w6) & 1.5 & 20 \\
a-Linoleic (18:3 w3) & 1.6 & 2 \\
Arachidonic acid (20:4 w6) & 0.9 & - \\
EPA (20:5 w3) & 15.5 & - \\
DHA (22:6 w3) & 9.1 & - \\
Oleic (18:1 w9) & 11.4 & 33 \\
Palmitic (C:16:0) & 17.1 & 30 \\
Stearic (C18:0) & 2.8 & 13 \\
\hline
\end{tabular}

alanine aminotransferase (ALT) and aspartate aminotransferase (AST) measurement. The rats were sacrificed under diethyl ether anesthesia. The liver of each rat was excised for histopatologic and cell cycle phases analysis as well as cellular proliferationregeneration index using flow cytometry.

\section{Assessment of liver function}

The blood samples were centrifuged (Beckman GS -6R, Germany) at $4{ }^{\circ} \mathrm{C}$ for 15 minutes to separate serum. Serum ALT and AST activities were determined as international unit per litre (IU/L) by a Hitachi 747 automatic analyzer (Hitachi, Tokyo) using commercial kits.

\section{Histological analysis}

Liver samples fixed in $10 \%$ buffered formalin were embedded in paraffin, sliced into $5 \mu \mathrm{m}$ sections, and stained with hematoxylin-eosin for histological assessment by a registered pathologist unaware of the treatments. The histopathological changes were examined under the microscope (Nikon, Eclipse, TS100, Japan).

Cell - cycle phases analysis and cell proliferation-regeneration assay by flow cytometry

Fresh tissue was disintegrated mechanically at $4{ }^{\circ} \mathrm{C}$ in a plastic Petri dish which contains medium (RPIM, $1640+5 \%$ fetal calf serum). Cell suspension was slipped by a filter with $80 \mu$ sized pores and suspended at ice containing $0.1 \%$ triton $\mathrm{x}-100 \mathrm{PBS}$ for 3 minutes. After ablution, cell suspension was incubated at $37^{\circ} \mathrm{C}$ with RNA'z for 20 minutes (180 U/mL PBS). Then stored in the dark for 1 hour at $4{ }^{\circ} \mathrm{C}$ with propidiumiodide $(50 \mu \mathrm{g} / \mathrm{ml}$ in PBS) and flow cytometric analysis (FCA) were performed with Epics Elite EST (Coulter - USA ).

G0 / G1, S, G2 / M phases of the cells and DNA distribution of the cell cycle fractions were calculated with DNA polipoidi index Multi Cycle DNA computer program. (Phoenix flow systems, Inc. San Diego). These values were interpreted as the proliferative - regenerative index (PI). PI was expressed as percentage fraction of the division of sum of $\mathrm{S}$ phase and rate between $\mathrm{G} 2$ and $\mathrm{M}$ phases with sum of rate between $\mathrm{G} 0$ and $\mathrm{G} 1$ phases, $\mathrm{S}$ phase and rate between $\mathrm{G} 2$ and $\mathrm{M}$ phases. $\mathrm{PI}=(\mathrm{S}+\mathrm{G} 2 / \mathrm{M}) \div(\mathrm{G} 0 /$ $\mathrm{G} 1+\mathrm{S}+\mathrm{G} 2 / \mathrm{M}) \mathrm{X} 100$ (19).

\section{Statistical analysis}

Statistical analysis of the results was performed using the Mann-Whitney U-test, analysis of variance (ANOVA) and the Student's t- test. The results are expressed as the mean \pm SEM and a $\mathrm{pP}$ value $<0.05$ was considered significant.

\section{Results}

\section{Biochemical results}

The serum ALT and AST levels of the study groups are presented in the Table 2. No significant difference at AST - ALT levels of control and FO groups were found. AST - ALT levels of $\mathrm{CC1}_{4}$ and $\mathrm{FO}-\mathrm{CC1}_{4}$ groups were significantly higher than in the control 
Tab. 2. Serum levels of alanine and aspartate aminotransferases of study groups.

\begin{tabular}{lcc}
\hline Group & AST (IU/L) & ALT (IU/L) \\
\hline Control (SRF+Salin) & $132,67 \pm 11,96$ & $36,8 \pm 4,48$ \\
CC14 (SRF+CC14 ) & $363,14 \pm 22,14^{\mathrm{a}, \mathrm{b}}$ & $241,20 \pm 5,82^{\mathrm{a}, \mathrm{b}}$ \\
Fish Oil (SRF+\%20 Fish oil) & $128,60 \pm 10,60$ & $33,47 \pm 4,27$ \\
Fish oil - CC14 & $531,13 \pm 28,07^{\mathrm{c}}$ & $412,40 \pm 32,98^{\mathrm{c}}$ \\
(SRF+\%20 Fish oil+CC14) & &
\end{tabular}

${ }^{a} p<0.01 ;{ }^{b} p<0.01$ as compared with control and fish oil group; ${ }^{\mathrm{c}} \mathrm{p}<0.01$ as compared with $\mathrm{CC}_{4}$ group; SRF: Standard rat feed. Values are given as the mean \pm SEM

and FO groups $(\mathrm{p}<0.01,0.01)$. In addition AST - ALT levels of FO- $\mathrm{CC1}_{4}$ was significantly higher than in $\mathrm{CC}_{4}$ group $(\mathrm{p}<0.01)$.

\section{Histological analysis}

In the control and FO group, no changes were observed in the hepatocytes, portal triad, sinusoidal structures, central vein, and hexagonal liver lobules. Almost no ballooning degenerations were observed (Figs 1 and 2).

All rats given $\mathrm{CCl}_{4}$ or $\mathrm{FO}-\mathrm{CCl}_{4}$ showed histopathological signs of acute hepatitis, reflected by necrosis, inflammatory cell infiltrate, ballooning degeneration and hemorrhage. Liver damage

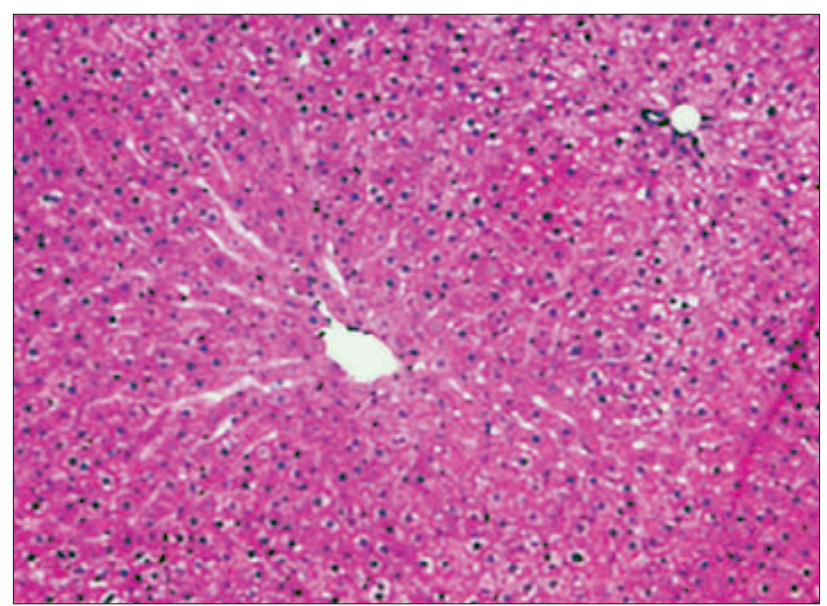

Fig. 1. Group Control (SRF-saline) (H\&E x100).

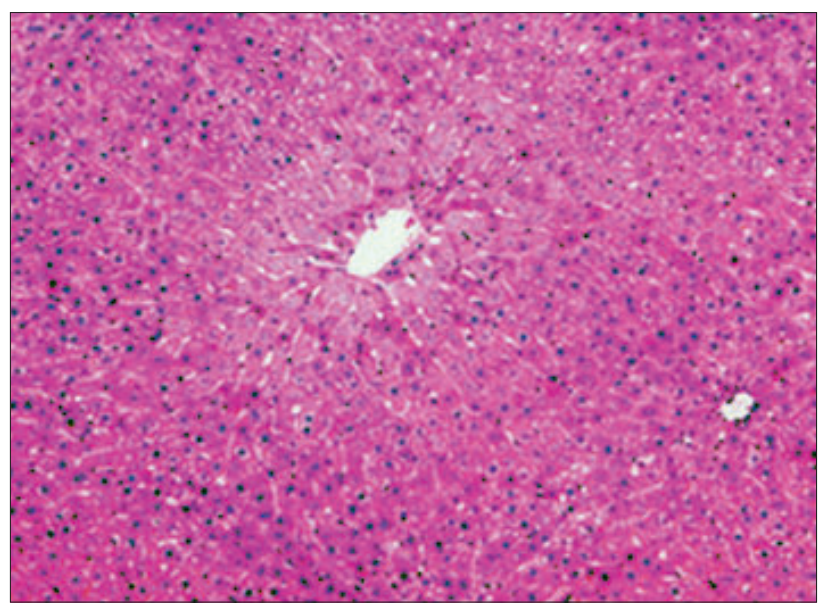

Fig. 2. Group Fish oil (FO-saline) (H\&E x100). and histological changes were found to be significantly worse in the $\mathrm{FO}-\mathrm{CCl}_{4}$ group than $\mathrm{CC}_{4}$ group (Figs 3 and 4).

Cell - cycle phases and cell proliferation-regeneration analysis of liver by flow cytometry

Liver cell-cycle phases and proliferation analysis of experimental groups are presented in the Table 3. Despite an increase in the proportion of the synthese phase $(\mathrm{S})$ cells and proliferation index (PI) and a decrease in the proportion of G0/G1 phase cells in the $\mathrm{CCl}_{4}$ group, the differences were not statistically significant when compared to the control group $(\mathrm{p}>0.05)$. When FO group was compared tothe control group; percentage of cells in S phase and PI was significantly decreased ( $\mathrm{p}<0.001,0.001$ respectively) and the rate of $\mathrm{G} 0 / \mathrm{Gl}$ phase cells was significantly increased $(\mathrm{p}<0.0001)$. In comparison of fish oil and $\mathrm{CC}_{4}$ groups; PI and the percentage of cells in $\mathrm{S}$ phase was significantly decreased ( $\mathrm{p}$ $<0.001,0.001$ respectively) and rate of G0/G1 phase cells was significantly increased ( $\mathrm{p}<0.001$ respectively). When $\mathrm{FO}-\mathrm{CC}_{4}$ group was compared to the control group; the rate of $\mathrm{S}$ and $\mathrm{G} 2$ phase cells and PI was significantly decreased $(p<0.001,0.001,0.001$ respectively) and the rate of $\mathrm{G} 0 / \mathrm{Gl}$ phase cells was significantly

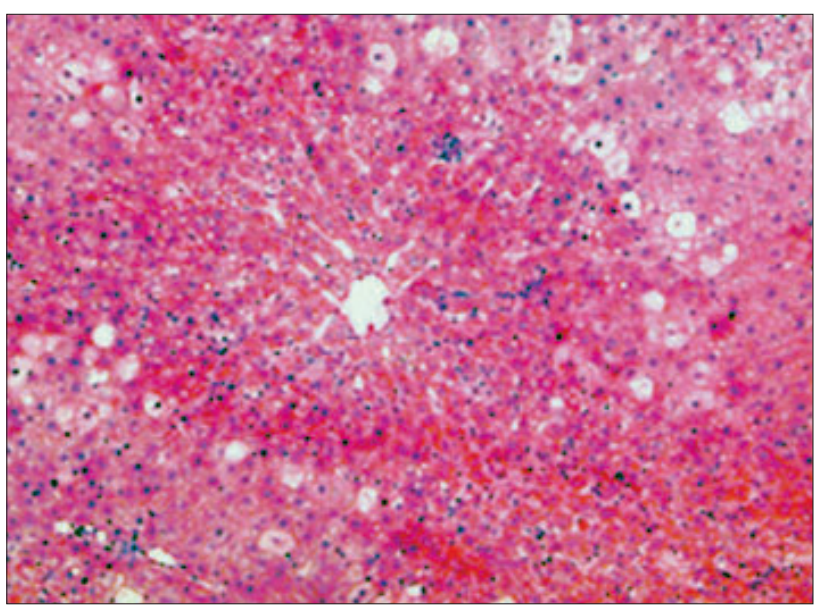

Fig. 3. Group CC14 (SRF- C14) (H\&E x100).

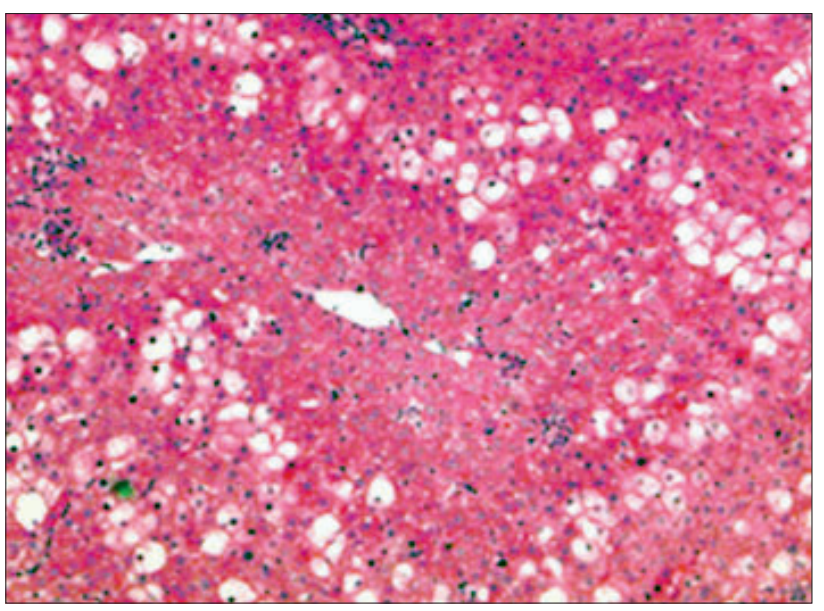

Fig. 4. Group FO-CC14 (H\&E x100). 
Tab. 3. Liver cell- cycle phases and proliferation analysis of experimental groups by flow cytometry.

\begin{tabular}{|c|c|c|c|c|}
\hline & Control & CC14 & FO & $\mathrm{FO}+\mathrm{CCL} 4$ \\
\hline$\overline{\mathrm{G} 0 / \mathrm{G} 1(\%)}$ & $69,91 \pm 0,94$ & $66,82 \pm 0,92^{\mathrm{b}}$ & $77,27 \pm 0,96^{\mathrm{a}}$ & $85,34 \pm 1,13^{\mathrm{abc}}$ \\
\hline S (\%) & $21,07 \pm 0,79$ & $23,65 \pm 0,84^{\mathrm{b}}$ & $13,42 \pm 0,61^{\mathrm{a}}$ & $9,26 \pm 0,93^{\mathrm{abc}}$ \\
\hline G2/M (\%) & $9,02 \pm 0,50$ & $8,53 \pm 0,27$ & $9,17 \pm 0,52$ & $5,42 \pm 0.42^{\mathrm{abc}}$ \\
\hline PI & $30,09 \pm 1,71$ & $32,18 \pm 0,92^{\mathrm{b}}$ & $22,59 \pm 0,96^{\mathrm{a}}$ & $14,67 \pm 1,13^{\mathrm{abc}}$ \\
\hline
\end{tabular}

increased $(\mathrm{p}<0.001)$. In the comparison of $\mathrm{FO}-\mathrm{CCl}_{4}$ and $\mathrm{CCl}_{4}$ groups; the rate of S and G2 phase cells and PI was significantly reduced ( $\mathrm{p}<0.001,0.001,0.001$ respectively) and the proportion of cells in Gl phase was significantly increased $(p<0.001)$. When FO- $\mathrm{CCl}_{4}$ group was compared with fish oil group; the rate of $\mathrm{S}$ and G2 phase cells and PI was significantly decreased ( $\mathrm{p}<0.002$, $0.001,0.001$ respectively) and the proportion of cells in Gl phase was significantly increased $(\mathrm{p}<0.001)$.

\section{Discussion}

During the past decade, dietary n-3 PUFAs have been the subject of numerous investigations. Despite some beneficial effects of n-3 PUFAs, several adverse effects are also documented (11, 12, 20).

In our study, dietary fish oil alone did not lead to any biochemical and histopathological changes in rat livers. All rats given $\mathrm{CC}_{4}$ or Fish oil plus $\mathrm{CC1}_{4}$ showed biochemical and histopathological signs of acute hepatitis. Data in our study also showed that fish oil diet increased the elevation of serum transaminase and the liver injury induced by $\mathrm{CCl}_{4}$. Similarly Nanji et al (21) and Polavarapu et al (14) found that fish oil caused severe liver damage in alcohol - intoxicated rats. They suggested that the feeding dietary substrates that enhance lipid peroxidation can exacerbate both ethanol-induced oxidative damage as well as necroinflammatory changes. Kurulay et al (22) also showed that fish oil increased hepatotoxic effects of acetaminophen. In contrast, Schmöcker et al. demonstrated that n-3 PUFA alleviate D-galactosamine/ lipopolysacharide-induced acute hepatitis by suppression of cytokines (7). Further Periz et al reported that DHA blunted liver injury induced by $\mathrm{CCl}_{4}(23)$.

Multiple cellular mechanisms have been purposed to explain the effects of n-3 PUFAs, including the inhibition of ARA-derived eicosanoid biosynthesis, influences on transcription factors and gene expression, modification of signal transduction pathway and enhancement of lipid peroxidation $(24,25)$.

Compensatory cell proliferation and tissue regeneration occurs as an endogenous response following either partial hepatectomy or chemical damage to the liver and enable animals to overcome injury and survive (26). In this study, $\mathrm{CCl}_{4}$ group showed that $\mathrm{CCl}_{4}$ enhanced PI and cells proliferation by accelerating the $\mathrm{G} 1$ to $\mathrm{S}$ progression at 24 hours. In the study performed by Rao et al (27), in which the rats were treated with $\mathrm{CCl}_{4}$, the authors investigated that following administration of $\mathrm{CCl}_{4}$, the peak S-phase synthesis was observed at $36 \mathrm{~h}$, indicating maximum DNA synthesis occurred at this time point. Our results also showed that fish oil prevented cell proliferation in Fish oil or Fish oil plus $\mathrm{CCl}_{4}$ administrated rats, increased the proportion of cells in the G0/G1phase and decreased the proportion of cells in the $\mathrm{S}$ phase suggesting that Fish oil in rich n-3 PUFAs prevented cell proliferation by decelerating the G1 to S progression.

Similarly, several in vitro studies have demonstrated that fish oil diet rich in n-3 PUFAs inhibited proliferation of normal and malignant cells $(17,18,28)$. In the in vitro study by Noorden et al (29), the fish oil diet has been found to reduce the compensatory growth after partial surgical hepatectomy in parallel to increased lipid peroxidation. Arend et al (30) also demonstrated that a diet enriched with fish oil enhanced lipidperoxidation and suppressed reparative regeneration of the rat liver connective tissue. Recently, Chung Chiang et al (31) showed that fish oil caused inhibition of hepatoblastoma cell proliferation. In contrast, some studies have shown that PUFAs promoted cell proliferation $(15,16)$. At present, the exactly reason is not known. However, these differences between the experimental studies may result from a different experimental set up, for example, species used, sex and age of the animal, the period and dose of experimental treatment.

It should be noted that one of the limitations of the present study is the lack of data on lipid peroxidation antioxidant status and inflammatory mediators (TNF- $\alpha$, IL- $1 \beta$, IFN- $\gamma$, nitric oxide), regarding the measurements of antioxidants such as superoxide dismutase, glutathione and malondialdehyde of thiobarbituric acid reactive substances. Our results can be interpreted that fish oil can slow down cell renewal or, by deepening cell damage, it may emerge a decreased proliferation index and the synthesis phase.

In conclusion, in the present CCl4-induced acute hepatic injury model of rats, fish oil diet exacerbated the hepatic injury and prevented cell proliferation-regeneration in normal and injured liver cells. Suppression of tissue regeneration by fish oil may lead to the progression of hepatic injury.

\section{References}

1. Shah H, Hartman SP, Wienhouse S. Formation of carbonyl chloride in carbon tetrachloride metabolism by rat liver in vitro. Cancer Res 1979; 10: 3942-3947.

2. Basu S. Carbon tetrachloride-induced lipid peroxidation: eicosanoid formation and their regulation by antioxidant nutrients. Toxicology 2003; 189: 113-127.

3. McGregor D, Lang M. Carbon tetrachloride: genetic effect and other modes of action. Mutat Res 1996; 366:181-195.

4. Zhang LJ, Yu JP, Li D, Huang YH. Effects of cytokines on Carbon tetrachloride-induced hepatic fibrogenesis in rats. World J Gastroenterol 2004; 10 (1): 77-81.

5. Lee TH, Hoover RL, Williams JD et al. Effect of dietary enrichment with eicosapentaenoic and docosahexaenoic acids on in vitro neutrophil and monocyte leukotriene generation and neutrophil function. N Engl J Med 1985; 312 (19): 1217-1224.

6. Funk CD. Prostaglandins and leukotrienes: advances in eicosanoid biology. Science 2001; 294: 1871-1875.

7. Schmöcker C, Weylandt KH, Kahlke L, Whang J, Lobeck H, Tiegs G, Berg T, Kang JX. Omega-3 fattye acids aleviate chemically induced acute hepatitis by suppression of cytokines. Hepatology 2007; 45: 864-869. 
8. Hao W, Wong OY, Liu X, Lee P, Chen Y, Wong KKY. Omega-3 fatty acids suppress inflammatory cytokine production by macrophages and hepatocytes. J Pediatr Surg 2010; 45: 2412-2418.

9. Calder PC. Dietary modification of inflammation with lipids. Proc Nutr Soc 2002; 61: 345-358.

10. Albina JE, Gladden P, Walsh WR. Detrimental effects of an omega-3 fatty acid-enriched died on wound healing. J Parenteral Nutr 1993; 17: 519-521.

11. Hoitinga JR, Werschuren PM, Meijer GW, Wiersma A. The association of increasing dietary concentration of fish oil with hepatotoxic effects and a higher degree of aorta atherosclerosis in the ad lib-fed rabbit. Food Chem Toxicol 1998; 36: 663-672.

12. Song JH, Miyazawa T. Enhanced level of n-3 fatty acid in membrane phospholipids induces lipid peroxidation in rats fed dietary docosahexaenoic acid oil. Atherosclerosis 2001; 155: 9-18.

13. Yasuda S, Whatanabe S, Kobayashi T, Okuyama H. Docosahexaenoic acid-rich fish oil does not enhance the elevation of serum transaminase and liver triacylglycerol induced by carbon tetrachloride in mice. Lipids 1997; 32: 1249-1255.

14. Polavarapu R, Spitz DR, Sim JE, Follansbee MH. Increased lipid peroxidation and impaired antioxidant enzyme function is associated with pathological liver injury in experimental alcoholic liver disease in rats fed diets high in corn oil and fish oil. Hepatology 1998; 27: 1317-1323.

15. Liu WM, Shi FX, Lu LZ, Zhang C, Liu YL. Effects of linoleic acid and eicosapentaenoic acid on cell proliferation and lipid-metabolism gene expression in primary duck hepatocytes. Mol Cell Biochem 2011; 352: $19-24$.

16. Yonezawa T, Haga S, Kobayashi Y, Katoh K, Obara Y. Unsaturated fatty acid promote proliferation via ERK $1 / 2$ and Akt pathway in bovine mammary epithelial cells. Biochem Biophys Res Commun 2008; 367: 729-735.

17. Maurin AC, Cheavassieux PM, Vericel E, Meunier PJ. Role of polyunsaturated fatty acids in the inhibitory effect of human adipocytes on osteoblastic proliferation. Bone 2002; 31: 260-266.

18. Van Beelen VA, Roeleveld J, Mooibroek H, Sijtsma L, Bino RJ, Bosch D. A comparative study on the effect of algal and fish oil on viability and cell proliferation of Caco-2 cells. Food Chem Toxicol 2007; 45 (5): 716-724.

19. Riley RS, Mahın EJ, Ros W. DNA Ploidy and cell cycle analysis. In: Clinical applications of flow cytometry Eds. Riley RS, Mahin RJ. Ros W. Igaku-Snoin. New York - Tokyo, 1993 pp. 251-322.
20. Schmit EB. n-3 fatty acids and the risk of coronary heart disease. Dan Med Bull 1997; 44: 1-22.

21. Nanji AA, Zahao S, Zadrezadeh SM, Dannenberg AJ, Tahan SR. Markedly enhanced cytochrome P450 2E1 induction and lipid peroxidation is associated with severe liver injury in fish oil-ethanol-fed rats. Alcohol Clin Exp Res 1994; 18: 1280-1285.

22. Kurulay F, Akarca US, Özütemiz ÖA, Kutay F, Batur Y. Possible role of glutadhione in prevention of acetaminophen-induced hepatoxicitye enhanced by fish oil in male Wistar rats. Journal of Toxicology and Environmental Healthy 1998; 53: 223-229.

23. Periz A, Planaguma A, Gronert K, Miquel R, Parra LM. Docosa hexaenoic acid (DHA) blunts liver injury by conversion to protective lipid mediators: protectin D1 and 17S-Hydroxy-DHA. FASEB J 2006; 20: 1844-1855.

24. Shaikh SR, Edidin M. Polyunsaturated fatty acids membrane organization, T cells and antigen presentation. Am J Clin Nutr 2006; 84: $1277-1289$.

25. Schley PD, Brindley DN, Field CJ. (n-3) PUFA alter raft lipid composition and decrease epidermal growth factor receptor levels in lipid rafts of human breast cancer cells. J Nutr 2007; 137: 548-553.

26. Pistoi S, Morello D. Liver regeneration 7.promedheus myth revisited: transgenic mice as a powerful tool to study regeneration. FASEB J 1996; 10: 819-828.

27. Roa PS, Mangipudy RS, Mehendale HM. Tissue injury and repair as parallel and opposing responses to $\mathrm{CCl} 4$ hepatotoxicity: a noel doseresponse. Toxicology 1997; 118: 181-193.

28. Terry PD, Terry JB, Rohan TE. Long-chain (n-3) fatty acid intake and risk of cancers of the breast and the prostate: recent epidemiological studies, biological mechanisms, directions for future research. J Nutr 2004; 134: 3412-3420.

29. Noorden CJF. Effects of n-3 and n-6 polyunsaturated fatty acid- enriched diets on lipid metabolism in periportal and pericentral compartments of female rat liver lobules and the consequences for cell proliferation after partial hepatectomy. J Lipid Res 1995; 36: 1708- 1720.

30. Arend A, Zilmer M, Vihalemm T, Selstam G. Lipoic acid prevents suppression of connective tissue proliferation in the rat liver induced by n-3 PUFAs. Ann Nutr Metab 2000; 44: 217-222.

31. Chiang KC, Persons KS, Istfan NW, Holick M, Chen TC. Fish oil enhances the antiproliferative effect of $1 \alpha, 25$-Dihydoxyvitamin $\mathrm{D}_{3}$ on liver cancer cells. Anticancer Res 2009; 29: 3591-3596. 